\title{
US rules hinder research on disposal of PCBs
}

Washington. The US Environmental Protection Agency (EPA) is reviewing its restrictions on the use of toxic chemicals known as polychlorinated biphenyls (PCBs). The new rules could make it easier and less expensive for scientists to conduct research on removing PCBs from the environment.

The current regulations are especially bothersome to scientists who have developed effective techniques in the laboratory. Such researchers have found it difficult if not impossible to obtain soil laced with PCB or to receive permission to carry out tests at a contaminated site.

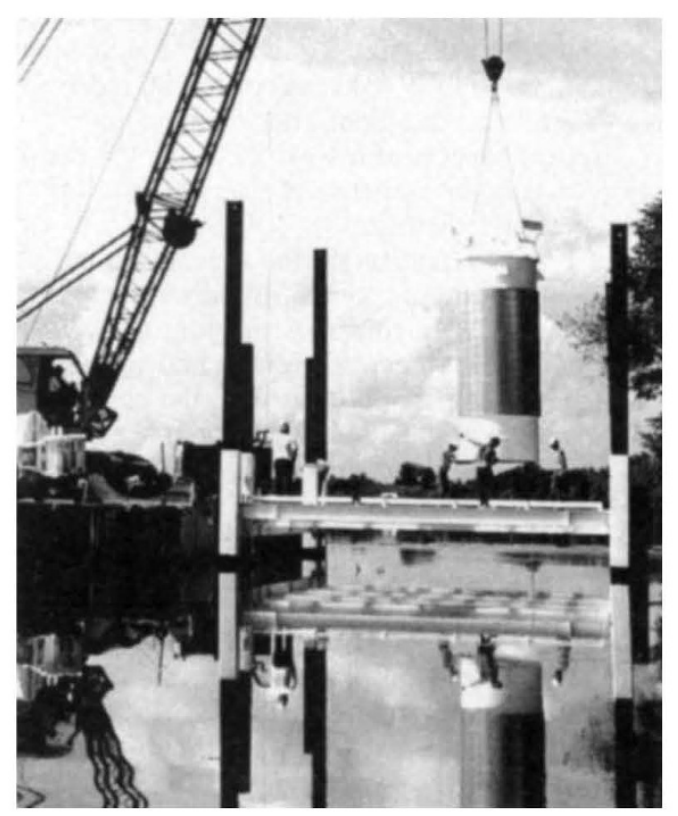

These steel caissons create a laboratory on the floor of the Hudson River.

Daniel Abramowicz, manager of the bioremediation laboratory at General Electric (GE)'s Research and Development Center in Schenectady, New York, says that it has been "a research nightmare" to do experiments with PCBs, widely used in electrical power equipment until the 1970 s. GE researchers have had to wait as much as a year or more to receive crucial permits and have been barred from exchanging samples. Although a procedure for $\mathrm{PCB}$ bioremediation has already performed successfully in several field trials, its progress is stymied by EPA regulations.

Scientists working with other toxic chemicals face similar problems only if they want to test their disposal techniques on large amounts of hazardous waste. Most toxic chemicals are exempt from onerous regulations if only small amounts of the substance are used, and the EPA is thinking about raising the level at which researchers lose their exemption.

But $\mathrm{PCB}$ regulations, which are based on the Toxic Substances Control Act (TSCA) passed in the late 1970 s, provide no such exemption. As a result, some researchers say that PCBs are far more tightly regulated than is necessary to protect the environment and human health.

For example, EPA rules dictate that scientists can work only with PCBs "originally packaged in...hermetically sealed containers of no more than five milliliters." The rule forces researchers to buy PCBs from commercial suppliers, although many of the compounds can be easily synthesized. The 'original packaging' standard also prevents researchers from working with waste-site samples. As a result, scientists often use their expensive, purchased PCBs to contaminate soil and water samples in the laboratory despite an abundance of the real thing.

Researchers can obtain exemptions from the packaging standard, but obtaining a permit is an expensive and arduous process that can take up to a year. "The permit process is designed more for industry," says Pamela Morris, who works on PCB bioremediation at the EPA laboratory in Gulfbreeze, Florida. "They wanted me to have an engineering-scale diagram of my technology unit. Basically, I'm doing microbiology in a flask." Morris was unable to do important experiments during a sixmonth wait for her permit.

Those with a permit face a morass of regulations on the transportation, handling and disposal of PCB samples. Even relatively small samples of PCB soil must be shipped in a hazardous waste tanker truck at a cost that may reach thousands of dollars. EPA rules also require detailed accounts of how the materials are used and disposed of. EPA officials acknowledge that exemptions for researchers working with small quantities of PCBs make sense, and they plan to release new regulations for comment by the end of the year.

The changes will come none too soon: last year, the agency found more than 34 million cubic yards of PCB-tainted material at 1,200 of the country's most polluted dump sites. But the only options now available are to burn the material or dump it in an approved landfill. Relaxing its mandate to prevent PCB pollution would allow EPA to help those trying to find more and better ways to repair the environmental damage.
NEWS IN BRIEF

London. Anyone still interested in the research on cold fusion being carried out by chemists Martin Fleischmann and Stanley Pons are likely to find it harder than ever to get their hands on the data. Speaking last week in Southampton at the annual meeting of the British Association for the Advancement of Science,

Fleischmann said that the pair now work for an "industrial concern", a Japanese think-tank called Technova Inc., and that they must take commercial considerations into account before discussing their work. However, Fleischmann would not say what might be commercially sensitive about the work, how it extends the experiments that caused a media storm in 1989 or how much money Technova was investing. He did say that a new laboratory was being built somewhere in France but refused to identify the site except to point out that it was "very nice" there.

I.M.

Washington. A two-year congressional investigation of accounting practices at US research universities has revealed an arcane and capricious accounting system that permits large differences in what universities charge the government for the cost of supporting research.

Last week's report, by the General Accounting Office (GAO), does not contain any scandals similar to those uncovered in 1989 and 1990. Instead, it focuses on the two agencies - the Office of Nava! Research (ONR) and the Department of Health and Human Services (HHS) - that share auditing duties for about 600 research universities. Those assigned to ONR can charge an indirect cost rate that averages one-fifth higher than those assigned to HHS. Overall, GAO calculates that US universities have overcharged the government by at least $\$ 400$ million. (The universities disagree, and have returned or withdrawn about $\$ 16$ million.)

$\mathrm{GAO}$ recommends that one agency oversee the system to make it more consistent. It also recommends that the government include university representatives in negotiations now under way. Although the report calculates the probable impact of various alternatives (one possibility - a flat 50 per cent indirect cost rate - would cut research indirect cost funding by $\$ 84$ million for a sample of 137 universities), It does not recommend a specific option.

Washington. A small bolt was apparently to blame for the failure of last month's joint US and Italian space mission (see Nature 358,$529 ; 1992$ ) to release a tethered satellite. Investigators at the US National Aeronautics and Space Administration (NASA) reported last week that the boit, which was added to the tether structure earlier this year to strengthen it for launch, apparently interfered with the tether's winding mechanism and prevented it from extending the full 12 miles. The satellite ventured only 840 feet from the space shuttle.

Traci Watson 